\title{
Practical Considerations for Perforator Flap Thinning Procedures Revisited
}

\author{
Theddeus OH Prasetyono ${ }^{1}$, Kristaninta Bangun ${ }^{1}$, Frank B Buchari ${ }^{2}$, Putri Rezkini ${ }^{1}$ \\ ${ }^{1}$ Division of Plastic Surgery, Department of Surgery, Cipto Mangunkusumo Hospital, University of Indonesia, Jakarta; ${ }^{2}$ Division of Plastic \\ Surgery, Department of Surgery, Adam Malik Hospital, Faculty of Medicine University of North Sumatra, Medan, Indonesia
}

Background A thin perforator flap is one of the best methods for covering defects. This study aimed to revisit and further test the rapidly advancing field of flap thinning techniques.

Methods We performed two cadaveric studies to test the known flap thinning methods, and then applied these methods to a clinical series. In the first study, five cadavers were used to observe the anatomical relation of the perforator with the subdermal plexuses and the subcutaneous fat layer by injecting a colored latex solution. The second study was done on four cadavers independently from the first study. Last, a clinical series was performed on 15 patients.

Results The areolar fat lobules of 10 anterolateral thigh perforator (ALT), seven deep inferior epigastric artery perforator (DIEAP), and six thoracodorsal artery perforator (TAP) flaps were dissected to reduce the flap thickness guided by the colored vascular pattern. On average, the ALT, DIEAP, and TAP flaps were reduced to $32.76 \% \pm 9.76 \%, 37.01 \% \pm 9.21 \%$, and $35.42 \% \pm$ $9.41 \%$, respectively. In the second study, the areolar fat lobules were directly dissected in six ALT, six TAP, and four MSAP flaps, and an average reduction in flap thickness of $53.41 \% \pm$ $5.64 \%, 52.30 \% \pm 2.88 \%$, and $47.87 \% \pm 6.41 \%$, respectively, was found. In the clinical series, 13 out of the 15 cases yielded satisfactory outcomes with an average thickness reduction of $37.91 \% \pm 7.15 \%$.

Conclusions These multiple studies showed that the deep fat layer could be safely removed to obtain a thin yet viable perforator flap. This evidence suggests that the macroscopic flap thinning technique can achieve thin flaps. Surgeons should consider this technique before embracing the latest technique of supermicrosurgery.

Keywords Microsurgery / Microvessels / Perforator flap / Subcutaneous fat / Surgical flaps
Correspondence:

Theddeus $\mathrm{OH}$ Prasetyono

Division of Plastic Surgery, Department of Surgery, Cipto

Mangunkusumo Hospital, Faculty of

Medicine University of Indonesia,

Medical Staff Building 4th floor,

J. Diponegoro 71, Jakarta 13410, Indonesia

Tel: +62-817-858-899

Fax: +62-21-3190-3152

E-mail: teddyohprasetyono@yahoo. com

Part of this study was presented in the 14th Association of Southeast Asian Nations (ASEAN) Congress of Plastic Surgery (ACPS) in conjunction with 12th Annual Scientific Meeting of the Indonesian Association of Plastic Surgeons, Jakarta, Indonesia (May 9-11, 2008); the 15th World Congress of International Confederation for Plastic, Reconstructive and Aesthetic Surgery (IPRAS), New Delhi, India (November 29-December 3, 2009); and at the 11th Triennial Congress of International Federation of Society for Surgery of the Hand (IFSSH), Seoul, Republic of Korea (November 31-December 4, 2010).

No potential conflict of interest relevant to this article was reported.

Received: 27 Jun $2014 \bullet$ Revised: 27 Jul 2014 • Accepted: 4 Aug 2014

pISSN: 2234-6163 • elSSN: 2234-6171 • http://dx.doi.org/10.5999/aps.2014.41.6.693 • Arch Plast Surg 2014;41:693-701

\section{INTRODUCTION}

A perforator flap is one of the best modalities for covering defects to reduce donor site morbidity, particularly when compared to conventional microsurgical flaps. However, a thick and bulky skin flap does not give a favorable aesthetic outcome. To achieve a good aesthetic result, the flap should be thin and pliable yet viable [1-4]. This kind of flap is essential, particularly when covering defects in areas composed of thin skin such as the dorsal side of the hand, the head and neck regions $[2,5]$, and the dorsal side of the foot.

Traditionally, secondary debulking procedures have been nec- 
essary to achieve a thin yet viable flap. These secondary procedures were performed to avoid jeopardizing the flap vascularization, if the thinning procedures were carried out at the time of flap harvesting. However, a one-stage procedure that can achieve an ideal thin and pliable skin flap has been considered more beneficial. Kimura [6] suggested a one-stage flap thinning procedure that completely thinned the flap by defatting it using a microdissection technique under a microscope. This technique is thought to yield a thin yet viable flap using meticulous steps. However, flap thinning procedure has since undergone considerable advances.

The latest technique came later to achieve a thin flap without additional defatting procedures, but relies on a more distal yet smaller perforator vessel as the pedicle. This technique is challenging because it requires perforator-to-perforator vessel anastomosis, which is considered to reduce morbidities related to deep tissue dissection and the loss of major vessels. This advance technique is called the supermicrosurgery approach $[7,8]$. Using supermicrosurgery, surgeons are now able to harvest a thin flap just above the deeper fat layer that includes the superficial fascia [9] and anastomoses the perforator-to-perforator artery in the recipient site, including the accompanying vein. However, supermicrosurgery is relatively challenging for less experienced microsurgeons.

Therefore, we aimed to combine the flap thinning method with the latter two procedures mentioned above to enrich the repertoire of the flap thinning method. Specifically, our objective was to determine the relationship between perforator vessels, subdermal plexuses, and the subcutaneous fat layer to ease the flap thinning procedure macroscopically. Knowledge of the anatomical relationship of the subcutaneous fat layer with the perforator vessels and subdermal plexuses may allow microsurgeons to dissect the unnecessary fat layer to achieve a thin flap without having to perform an exhaustive and tedious dissection under a microscope.

\section{METHODS}

We report on two cadaveric studies and a clinical series. The first cadaveric study was performed to identify the anatomical relationship between the perforator vessels, subdermal plexuses, and the subcutaneous fat layer. The second study was a technical procedure that simulated the clinical surgical setting. It was conducted independently from the first cadaveric study to confirm the results of the first cadaveric study. Last, the subsequent clinical series was performed to test the feasibility of the macroscopic flap thinning procedures in a real clinical setting.

\section{Cadaveric study I}

In September 2006, a descriptive operational study was performed in a forensic laboratory on five fresh cadavers who were $\geq 18$ years old. These cadavers were unidentifiable at their time of death and might have been victims of accidents, neglected, or suffering from chronic illnesses and/or malnutrition.

The cadavers were placed on a table in the supine position and the anterolateral thigh perforator (ALT), deep inferior epigastric artery perforator (DIEAP), and thoracodorsal artery perforator (TAP) flaps were elevated. Flap thickness was measured, and the morphology of the fat lobules was examined. After the flaps were elevated, we injected a colored latex solution through the vessels with a 3-mL syringe and cannula number $24 \mathrm{G}$ or $26 \mathrm{G}$, depending on the vessel diameter. The colored latex solution was injected until the perforator arteries and subdermal plexuses were filled, which was indicated by the color that could be observed at the flap edges (Fig. 1). After 1 hour, the latex solution solidified. Based on the vascular pattern acquired, each of the flaps was thinned by a sharp dissection of the fat layer using scissors, while taking care to preserve the perforator vessel and subdermal plexus. The final thickness of the flaps was measured, and the morphology of the fat lobules was observed.

\section{Cadaveric study II}

To confirm the first cadaveric study, the second cadaveric study was performed in February 2007 in a forensic laboratory using four fresh cadavers with the same inclusion criteria as the first

Fig. 1. Flow of the colored latex through the subdermal plexus

The colored latex flowed from the subdermal plexus in the thoracodorsal artery perforator flap margin, as shown by the blue arrow. A, lamellar fat layer; $B$, the skin edge of the TAP flap; $C_{\text {, abdominal }}$ skin as the flap lies on the abdomen (as shown by the inset).

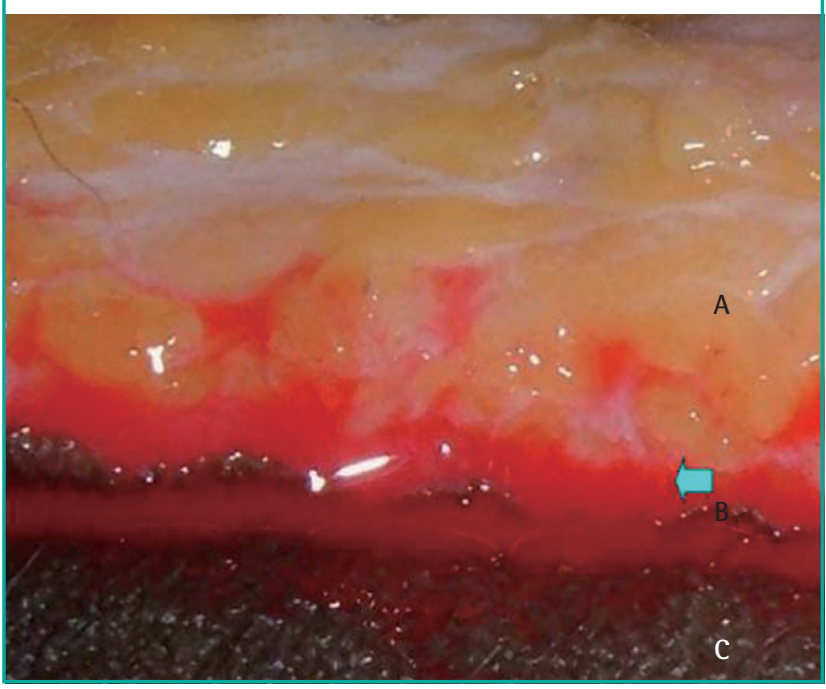


study. ALT, TAP, and the medial sural artery perforator (MSAP) flaps were elevated on both sides. Flap thickness was measured, and the morphology of the fat lobules was observed. Then, the thinning procedure was performed using scissors, but without the aid of a microscope. The procedure was carefully performed to preserve the superficial fat layer (areolar form) and excise the deeper fat layer (lamellar form), which was approximately 2-5 $\mathrm{mm}$ from the skin surface. Fig. 2 shows the different forms of the fat lobules. Additional effort was made to preserve the perforator vessels and subdermal plexus.

We injected a mixture of latex with $100 \mathrm{~g}$ of barium sulfate and $5 \mathrm{~g}$ of gelatin in $100 \mathrm{~mL}$ of $40^{\circ} \mathrm{C}$ hot water through cannula number $24 \mathrm{G}$ or $26 \mathrm{G}$ to the perforator artery using a $3-\mathrm{mL}$ syringe until the perforator vessels and subdermal plexus on the flap edges were filled. As in the first study, the solution was left to solidify for one hour. Subsequently, plain X-rays were taken to assess the reliability of flap vascularization according to the distribution of the visible contrast.

\section{Clinical series}

A subsequent clinical series of the macroscopic flap thinning procedure were performed following the cadaveric studies. From April 2007 to March 2009, 15 patients who had undergone free-flap surgery were included in our series (Table 1).

\section{Fig. 2. The form of the fat lobules}

The lamellar $(\mathrm{L})$ in the deep layer and areolar $(\mathrm{A})$ in the superficial layer.

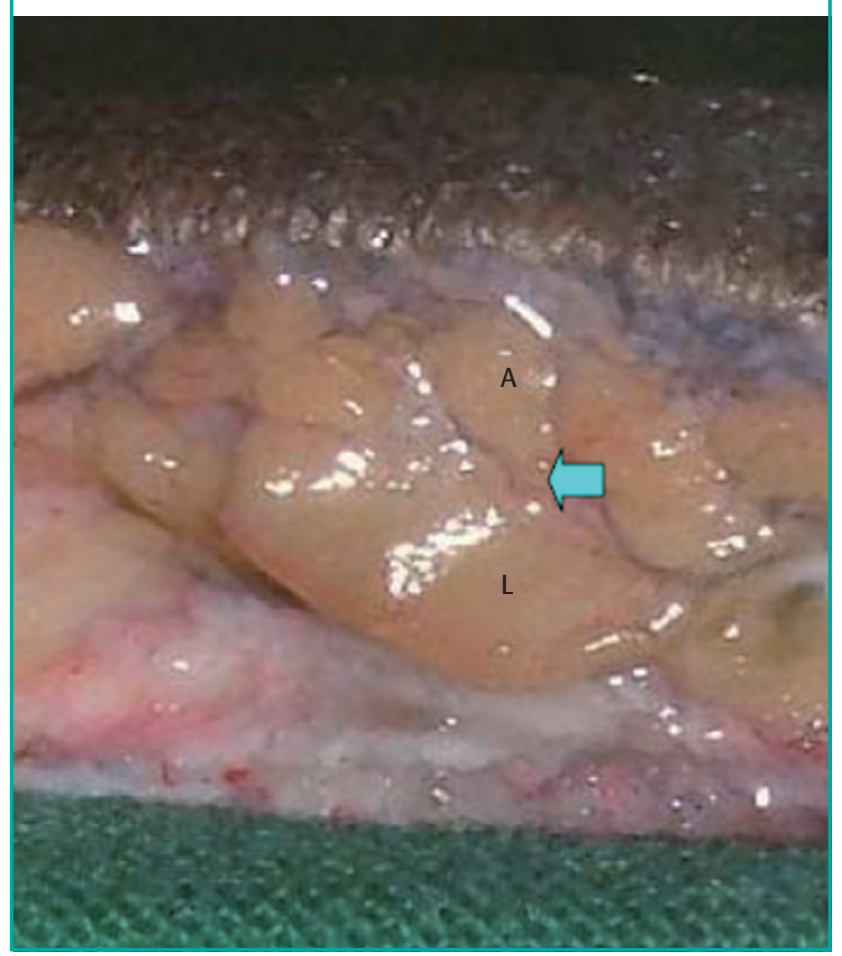

Only perforator skin flaps or fasciocutaneous flaps that required considerable thinning during surgery to fit each of the recipient sites requiring a thin flap procedure were used.

The flaps were thinned in situ either at the donor site before being transferred or at the recipient site right after vessel anastomosis was performed. The thinning procedure was performed by simply discarding the lamellar fat layer using scissors, but without the aid of a microscope. When deemed necessary, magnification using a $2.5 \times$ loupe was used when approaching the pedicle to ensure a 2 -cm cuff of lamellar fat tissue was left surrounding the perforator.

The pre- and post-thinning flap thicknesses were recorded as well as the time needed to thin the flap. The first author noted the viability of the flap as well as the subjective aesthetic outcomes and performed all of the surgeries on the patients discussed in this report.

\section{RESULTS}

\section{Cadaveric study I}

In this study, we elevated 23 flaps $(9 \mathrm{~cm} \times 15 \mathrm{~cm}$; 10 ALT, 7 DIEAP, and 6 TAP flaps) on five cadavers (Table 2). Three DIEAP and four TAP flaps were not available due to previous trauma on the cadavers' bodies.

The average thickness and reduction percentage of the ALT, DIEAP, and TAP flaps before and after the thinning procedure are listed in Table 3. On average, the ALT, DIEP, and TAP flaps were reduced to $32.76 \% \pm 9.76 \%, 37.01 \% \pm 9.21 \%$, and $35.42 \% \pm$ $9.41 \%$, respectively.

\section{Cadaveric study II}

Twenty-one flaps (7 ALT flaps, 8 TAP flaps, and 6 MSAP flaps) were elevated on four cadavers (Table 4). However, when the preserved tissue cuff was less than $2 \mathrm{~cm}$, there were errors in preserving the tissue cuff surrounding the perforator vessels. In the elevation of two MSAP and one ALT flaps, the perforator vessels were cut off. Due to these technical errors, these flaps were not assessed further.

The average thickness and reduction percentage of the ALT, TAP, and MSAP flaps before and after the thinning procedure are listed in Table 5. After the thinning procedure, which preserved $2 \mathrm{~cm}$ of the tissues surrounding the perforator vessels, the average thickness of the ALT, TAP, and MSAP flaps became $53.41 \% \pm 5.64 \%, 52.30 \% \pm 2.88 \%$, and $47.87 \% \pm 6.41 \%$, respectively, from their origin (Table 5).

Among the six successfully elevated ALT flaps, radiological examinations were only performed on four flaps. Two of the flaps' perforator vessels were very small (diameter $<0.5 \mathrm{~mm}$ ); thus, 
Table 1. Flaps profile of the clinical series

\begin{tabular}{|c|c|c|c|c|c|c|c|c|c|}
\hline No & $\begin{array}{l}\text { Age }(y r) / \\
\text { Sex }\end{array}$ & Problem & $\begin{array}{l}\text { Perforator } \\
\text { flap }\end{array}$ & $\begin{array}{c}\text { Flap } \\
\text { dimension } \\
\left(\mathrm{cm}^{2}\right)\end{array}$ & $\begin{array}{l}\text { Pre- } \\
\text { thinning } \\
\text { thickness } \\
(\mathrm{mm})\end{array}$ & $\begin{array}{l}\text { Post- } \\
\text { thinning } \\
\text { thickness } \\
\text { (mm) }\end{array}$ & $\begin{array}{l}\text { Post- } \\
\text { reduction } \\
\text { percentage } \\
(\%)\end{array}$ & $\begin{array}{l}\text { Length of } \\
\text { thinning } \\
\text { procedure } \\
\text { (min) }\end{array}$ & Outcome \\
\hline 1 & $25 / M$ & $\begin{array}{l}\text { Right foot dorsum } \\
\text { traumatic defect }\end{array}$ & ALTpf & $18 \times 12$ & 15 & 5.2 & 34.67 & 25 & $\begin{array}{r}\text { Flap survives; good } \\
\text { aesthetic contour }\end{array}$ \\
\hline 2 & $41 / \mathrm{M}$ & Left traumatic hand defect & ALTpf & $12 \times 8$ & 18 & 6.7 & 37.22 & 30 & $\begin{array}{r}\text { Flap survives; good } \\
\text { aesthetic contour }\end{array}$ \\
\hline 3 & $16 / F$ & $\begin{array}{l}\text { Hand dorsum defect post } \\
\text { injection induced necrosis }\end{array}$ & MSAPpf & $15 \times 8.5$ & 20 & 8 & 40 & 35 & Flap loss \\
\hline 4 & $21 / \mathrm{M}$ & $\begin{array}{l}\text { Right foot dorsum skin } \\
\text { avulsion }\end{array}$ & ALTpf & $12.5 \times 7$ & 29 & 10 & 34.48 & 35 & $\begin{array}{r}\text { Flap survives; good } \\
\text { aesthetic contour }\end{array}$ \\
\hline 5 & $24 / M$ & $\begin{array}{l}\text { Right foot dorsum skin } \\
\text { avulsion }\end{array}$ & ALTpf & $14 \times 8$ & 15 & 5 & 33.33 & 25 & $\begin{array}{l}\text { Flap survives; good } \\
\text { aesthetic contour }\end{array}$ \\
\hline 6 & $18 / \mathrm{M}$ & $\begin{array}{l}\text { Right foot dorsum skin } \\
\text { avulsion }\end{array}$ & ALTpf & $9 \times 8$ & 24 & 8 & 33.33 & 25 & $\begin{array}{l}\text { Flap survives; good } \\
\text { aesthetic contour }\end{array}$ \\
\hline 7 & $47 / F$ & Left diabetic foot defect & ALTpf & $18 \times 8$ & 16 & 5 & 31.25 & 35 & $\begin{array}{l}\text { Flap survives; good } \\
\text { aesthetic contour }\end{array}$ \\
\hline 8 & $30 / \mathrm{M}$ & $\begin{array}{l}\text { Right forearm electric } \\
\text { burn defect }\end{array}$ & ALTpf & $7 \times 5$ & 12 & 5 & 41.67 & 20 & Flap survives; bulky \\
\hline 9 & $27 / F$ & Neck contracture & ALTpf & $13 \times 15.5$ & 24 & 5.5 & 22.92 & 25 & $\begin{array}{l}\text { Flap survives; good } \\
\text { aesthetic contour }\end{array}$ \\
\hline 10 & $42 / F$ & Left diabetic foot defect & ALTpf & $24 \times 8$ & 13 & 5.5 & 42.31 & 30 & $\begin{array}{l}\text { Flap survives; good } \\
\text { aesthetic contour }\end{array}$ \\
\hline 11 & $27 / M$ & $\begin{array}{l}\text { Right burn hand } \\
\text { contracture and defect }\end{array}$ & ALTpf & $13 \times 9$ & 23 & 11 & 47.83 & 20 & $\begin{array}{l}\text { Flap survives; good } \\
\text { aesthetic contour }\end{array}$ \\
\hline 12 & $22 / \mathrm{M}$ & $\begin{array}{l}\text { Right forearm electric } \\
\text { burn defect }\end{array}$ & ALTpf & $17 \times 7$ & 17 & 9 & 52.94 & 20 & $\begin{array}{l}\text { Flap survives; good } \\
\text { aesthetic contour }\end{array}$ \\
\hline 13 & $44 / \mathrm{M}$ & Diabetic foot ulcer & ALTpf & $16 \times 12$ & 33 & 12 & 36.36 & 25 & $\begin{array}{l}\text { Flap survives; good } \\
\text { aesthetic contour }\end{array}$ \\
\hline 14 & $32 / F$ & Neck contracture & ALTpf & $18 \times 8$ & 26 & 10 & 38.46 & 25 & $\begin{array}{l}\text { Flap survives; good } \\
\text { aesthetic contour }\end{array}$ \\
\hline 15 & $27 / \mathrm{M}$ & Right 1st web contracture & ALTpf & $14 \times 6$ & 31 & 13 & 41.94 & 20 & $\begin{array}{r}\text { Flap survives; good } \\
\text { aesthetic contour }\end{array}$ \\
\hline
\end{tabular}

we could not insert the cannula.

From the six successfully elevated TAP flaps, only four were examined radiologically. The radiograph images showed a sufficient contrast distribution at the flap edges. Two flaps had perforator vessels that were $<0.5 \mathrm{~mm}$ in diameter.

All of the successfully elevated MSAP flaps had a contrast distribution at the flap edges (Fig. 3).

\section{Clinical series}

The 15 clinical series were performed at various locations, but mostly in the foot area. Table 1 presents the complete profile of these clinical cases. The average percentage of the post-thinning thickness was $37.91 \% \pm 7.15 \%$ (range, $22.9 \%-52.94 \%$ ). In addition, the time needed to thin the flap ranged from 20 to $35 \mathrm{~min}$ utes. The results of the thinning procedure are illustrated in Fig. 4, which shows the division of the two fat layers.

Thirteen out of fifteen cases yielded a satisfactory outcome as represented by the case shown in Fig. 5 . One $7 \mathrm{~cm} \times 5 \mathrm{~cm}$ ALT flap ended up being bulky, while one MSAP flap was lost due to venous thrombosis (Table 1).

\section{DISCUSSION}

The cadaveric studies were performed to determine the relationship between the perforator vessels, subdermal plexus, and the subcutaneous fat layers to facilitate the thinning of the flap. Although others have previously discussed this issue [6,7], the relationship among these structures has not been practically elucidated to provide a clear macroscopic cut-off point that can serve as a guide for the macroscopic thinning procedure of perforator flaps. Although Kimura et al. [10] also reported on the same division between the two fat layers, their flap thinning procedure was performed under a microscope.

We elevated the $9 \mathrm{~cm} \times 15 \mathrm{~cm}$ flaps in the cadaveric studies, assuming that these flaps could be supported with one perforator. Both studies showed that the diameter of the perforator vessels varied from $<0.5$ to $1.0 \mathrm{~mm}$. These observations were similar to those of Koshima et al. [2] who reported that the mean diameter of the perforator vessels ranges between $0.5 \mathrm{~mm}$ and 0.8 $\mathrm{mm}$. Hamdi et al. [3] stated that each perforator could support a DIEAP skin flap that is up to $33 \mathrm{~cm} \times 13 \mathrm{~cm}$ or a TAP flap that 
Table 2. Flaps profile in cadaveric study I

\begin{tabular}{|c|c|c|c|c|c|c|c|c|c|c|}
\hline \multirow{2}{*}{ Cadaver } & \multicolumn{2}{|c|}{ I } & \multicolumn{2}{|c|}{ II } & \multicolumn{2}{|c|}{ III } & \multicolumn{2}{|c|}{ IV } & \multicolumn{2}{|c|}{ V } \\
\hline & $\mathrm{L}$ & $\mathrm{R}$ & $\mathrm{L}$ & $\mathrm{R}$ & $\mathrm{L}$ & $\mathrm{R}$ & $\mathrm{L}$ & $\mathrm{R}$ & $\mathrm{L}$ & $\mathrm{R}$ \\
\hline \multicolumn{11}{|l|}{ ALT flap } \\
\hline No. of perforator & 2 & 3 & 4 & 3 & 2 & 3 & 3 & 4 & 3 & 2 \\
\hline Perforator type & $\mathrm{mc}$ & $\mathrm{mc}$ & SC & sc & $\mathrm{mc}$ & $\mathrm{mc}$ & mc & $\mathrm{mc}$ & $\mathrm{mc}$ & $\mathrm{mc}$ \\
\hline Diameter of perforator (mm) & 1 & 1 & $0.5-1$ & 1 & 1 & $0.5-1$ & $0.5-1$ & 1 & $<0.5$ & $<0.5$ \\
\hline \multicolumn{11}{|l|}{ Fat morphology } \\
\hline Deep & Lam & Lam & Lam & Lam & Lam & Lam & Lam & Lam & Lam & Lam \\
\hline Superficial & $\mathrm{Ar}$ & $\mathrm{Ar}$ & $\operatorname{Ar}$ & $\mathrm{Ar}$ & $\operatorname{Ar}$ & $\mathrm{Ar}$ & $\mathrm{Ar}$ & $\mathrm{Ar}$ & $\mathrm{Ar}$ & $\mathrm{Ar}$ \\
\hline \multicolumn{11}{|l|}{ Flap thickness (mm) } \\
\hline Pre-thinning & 12 & 12 & 13 & 12 & 10 & 8 & 18 & 18 & 21 & 21 \\
\hline Post-thinning & 4 & 4 & 4 & 5 & 4 & 4 & 5 & 5 & 4 & 4 \\
\hline Plexus distance from skin (mm) & 2 & 3 & 2 & 3 & 2 & 3 & 2 & 2 & 2 & 2 \\
\hline \multicolumn{11}{|l|}{ DIEAP flap } \\
\hline No. of perforator & 2 & - & 5 & 6 & - & 5 & 4 & 3 & 3 & - \\
\hline Perforator type & $\mathrm{mc}$ & - & $\mathrm{mc}$ & $\mathrm{mc}$ & - & $\mathrm{mc}$ & $\mathrm{mc}$ & mc & $\mathrm{mc}$ & - \\
\hline Diameter of perforator (mm) & 1 & - & 1 & $0.5-1$ & - & $0.5-1$ & 1 & $0.5-1$ & $<0.5$ & - \\
\hline \multicolumn{11}{|l|}{ Fat morphology } \\
\hline Deep & Lam & - & Lam & Lam & - & Lam & Lam & Lam & Lam & - \\
\hline Superficial & $\mathrm{Ar}$ & - & $\operatorname{Ar}$ & $\operatorname{Ar}$ & - & $\mathrm{Ar}$ & $\operatorname{Ar}$ & $\mathrm{Ar}$ & $\mathrm{Ar}$ & - \\
\hline \multicolumn{11}{|l|}{ Flap thickness (mm) } \\
\hline Pre-thinning & 14 & - & 12 & 12 & - & 8 & 14 & 14 & 8 & - \\
\hline Post-thinning & 5 & - & 4 & 4 & - & 4 & 4 & 4 & 4 & - \\
\hline Plexus distance from skin (mm) & 2 & - & 2 & 2 & - & 2 & 2 & 2 & 2 & - \\
\hline \multicolumn{11}{|l|}{ TAP flap } \\
\hline No. of perforator & - & 3 & 3 & 5 & 4 & 4 & - & - & - & 3 \\
\hline Perforator type & - & $\mathrm{mc}$ & mc & mc & mc & mc & - & - & - & $\mathrm{mc}$ \\
\hline Diameter of perforator (mm) & - & 1 & $0.5-1$ & $0.5-1$ & $0.5-1$ & $0.5-1$ & - & - & - & $<0.5$ \\
\hline \multicolumn{11}{|l|}{ Fat morphology } \\
\hline Deep & - & Lam & Lam & Lam & Lam & Lam & - & - & - & Lam \\
\hline Superficial & - & $\mathrm{Ar}$ & $\operatorname{Ar}$ & $\mathrm{Ar}$ & $\operatorname{Ar}$ & $\mathrm{Ar}$ & - & - & - & $\mathrm{Ar}$ \\
\hline \multicolumn{11}{|l|}{ Flap thickness (mm) } \\
\hline Pre-thinning & - & 8 & 12 & 12 & 8 & 8 & - & - & - & 6 \\
\hline Post-thinning & - & 3 & 3 & 3 & 3 & 3 & - & - & - & 3 \\
\hline Plexus distance from skin (mm) & - & 2 & 2 & 2 & 2 & 2 & - & - & - & 2 \\
\hline
\end{tabular}

Table 3. Average thickness of the elevated flaps in cadaveric study I

\begin{tabular}{|c|c|c|c|c|}
\hline & $\begin{array}{l}\text { Pre-thinning } \\
\text { thickness }(\mathrm{mm})\end{array}$ & $\begin{array}{l}\text { Post-thinning } \\
\text { thickness }(\mathrm{mm})\end{array}$ & $\begin{array}{l}\text { Post-reduction } \\
\text { percentage }(\%)\end{array}$ & $\begin{array}{l}\text { Standard } \\
\text { deviation }\end{array}$ \\
\hline ALT flap & 14.5 & 4.3 & 32.76 & 9.76 \\
\hline DIEAP flap & 11.7 & 4.1 & 37.01 & 9.21 \\
\hline TAP flap & 9.0 & 3.0 & 35.42 & 9.41 \\
\hline
\end{tabular}

is up to $30 \mathrm{~cm} \times 11 \mathrm{~cm}$. Gedebou et al. [4] reported that one perforator can support a skin flap having the dimensions of 18 $\mathrm{cm} \times 28 \mathrm{~cm}$. Wolff et al. [5] concluded that in the case of the ALT flap, one perforator can support a skin flap measuring 12 $\mathrm{cm} \times 30 \mathrm{~cm}$, while Chen et al. [1] reported these dimensions as $15 \mathrm{~cm} \times 35 \mathrm{~cm}$. Alkureishi et al. [11] recommended that one perforator can support an ALT skin flap measuring $17 \mathrm{~cm} \times 14$ $\mathrm{cm}$. All of this evidence supports the justification of the flap dimensions used in the present cadaveric studies.

Our observations revealed two morphologically different fat layers that were confined by the superficial fascia. The deeper layer had a lamellar form, and the superficial layer had an areolar form. This result is consistent with that reported by Gasperoni and Gasperoni [12]. The subdermal plexus was located superficially from the areolar fat layer. Based on this, Kimura and Satoh [13] performed fat layer thinning with the aid of a microscope, while preserving the areolar fat layer to avoid injuring the subdermal plexus. Gedebou et al. [4] and Wolff et al. [5] preserved a 1-2-cm fat layer around the perforator pedicle, while Alkureishi et al. [11] and Ross et al. [14] recommended preserving 
Table 4. Flaps profile in cadaveric study II

\begin{tabular}{|c|c|c|c|c|c|c|c|c|}
\hline \multirow{2}{*}{ Cadaver } & \multicolumn{2}{|c|}{ I } & \multicolumn{2}{|c|}{ II } & \multicolumn{2}{|c|}{ III } & \multicolumn{2}{|c|}{ IV } \\
\hline & $\mathrm{L}$ & $\mathrm{R}$ & $\mathrm{L}$ & $\mathrm{R}$ & $\mathrm{L}$ & $\mathrm{R}$ & $\mathrm{L}$ & $\mathrm{R}$ \\
\hline \multicolumn{9}{|l|}{ ALT flap } \\
\hline No. of perforators & 2 & - & 3 & 3 & 3 & - & 2 & 2 \\
\hline Perforator type & $\mathrm{mc}$ & - & SC & sc & $\mathrm{mc}$ & - & mc & $\mathrm{mc}$ \\
\hline Diameter of perforator (mm) & $<0.5$ & - & $0.5-1$ & 1 & $0.5-1$ & - & $0.5-1$ & $<0.5$ \\
\hline \multicolumn{9}{|l|}{ Flap thickness (mm) } \\
\hline Pre-thinning & 11 & - & 12 & 12 & 12 & - & 10 & 10 \\
\hline Post-thinning & 5 & - & 7 & 7 & 7 & - & 5 & 5 \\
\hline Pedicle thinning distance $(\mathrm{cm})$ & 2 & - & 2 & 2 & 2 & - & 2 & 2 \\
\hline Radiograph appearance & - & - & + & + & + & - & + & - \\
\hline Distribution of contrast to the flap edges & - & - & + & + & + & - & + & - \\
\hline \multicolumn{9}{|l|}{ TAP flap } \\
\hline No. of perforators & 3 & - & 4 & 3 & 4 & - & 3 & 3 \\
\hline Perforator type & $\mathrm{mc}$ & - & $\mathrm{mc}$ & $\mathrm{mc}$ & $\mathrm{mc}$ & - & $\mathrm{mc}$ & $\mathrm{mc}$ \\
\hline Diameter of perforator (mm) & 1 & - & 1 & 1 & $0.5-1$ & - & $<0.5$ & $<0.5$ \\
\hline \multicolumn{9}{|l|}{ Flap thickness (mm) } \\
\hline Pre-thinning & 16 & - & 14 & 14 & 15 & - & 15 & 14 \\
\hline Post-thinning & 8 & - & 7 & 7 & 8 & - & 8 & 8 \\
\hline Pedicle thinning distance $(\mathrm{cm})$ & 2 & - & 2 & 2 & 2 & - & 2 & 2 \\
\hline Radiograph appearance & + & - & + & + & + & - & - & - \\
\hline Distribution of contrast to the flap edges & + & - & + & + & + & - & - & - \\
\hline \multicolumn{9}{|l|}{ MSAP flap } \\
\hline No. of perforators & 1 & - & 1 & 2 & 3 & 2 & 1 & - \\
\hline Perforator type & $\mathrm{mc}$ & - & $\mathrm{mc}$ & $\mathrm{mc}$ & $\mathrm{mc}$ & - & mc & - \\
\hline Diameter of perforator (mm) & $0.5-1$ & - & 1 & 1 & 1 & - & $0.5-1$ & - \\
\hline \multicolumn{9}{|l|}{ Flap thickness (mm) } \\
\hline Pre-thinning & 8 & - & 9 & 8 & 8 & - & 8 & - \\
\hline Post-thinning & 4 & - & 5 & 4 & 3 & - & 4 & - \\
\hline Pedicle thinning distance (cm) & 1 & - & 2 & 2 & 2 & - & 2 & - \\
\hline Radiograph appearance & - & - & + & + & + & - & + & - \\
\hline Distribution of contrast to the flap edges & - & - & + & + & + & - & + & - \\
\hline
\end{tabular}

Table 5. Average thickness of the elevated flaps in cadaveric study II

\begin{tabular}{|c|c|c|c|c|}
\hline & $\begin{array}{l}\text { Pre-thinning } \\
\text { thickness }(\mathrm{mm})\end{array}$ & $\begin{array}{l}\text { Post-thinning } \\
\text { thickness }(\mathrm{mm})\end{array}$ & $\begin{array}{l}\text { Post-reduction } \\
\text { percentage }(\%)\end{array}$ & $\begin{array}{l}\text { Standard } \\
\text { deviation }\end{array}$ \\
\hline ALT flap & 11.17 & 6.00 & 53.41 & 5.64 \\
\hline TAP flap & 14.67 & 7.67 & 52.30 & 2.88 \\
\hline MSAP flap & 8.00 & 3.83 & 47.87 & 6.41 \\
\hline
\end{tabular}

2-cm of tissue surrounding the perforator pedicle to maintain the artery supply. In the second cadaveric study, we preserved a 2 -cm cuff of tissues surrounding the perforator vessels as recommended above $[11,14]$. This tissue preservation, according to Chen et al. [1], will help to prevent the perforator vessels from becoming twisted.

The mean thicknesses of the elevated flaps listed in Table 3 were slightly different from that reported by Nakayama et al. [15] who measured flap thickness in 31 patients using ultrasonography. The resulting thickness was $7.1 \pm 3.4 \mathrm{~mm}$ for ALT flaps and $13.7 \pm 7.9 \mathrm{~mm}$ for the DIEAP flaps [15]. In our first cadaveric study, the flaps were thinned based on the acquired vas- cular pattern, but without loupe magnification, and thin flaps were achieved with a thickness ranging from 3 to $4.3 \mathrm{~mm}$. This thickness is consistent with the results of previous reports about the safe limit of flap thinning $[1,6,13,16-19]$. However, in the second cadaveric study (Table 5), we could not produce a flap that was as thin as that produced in our first cadaveric study. The resulting thickness in the second study was relatively thicker because we were concerned about damaging the plexuses in the superficial fat layer. Nevertheless, the approach used in second cadaveric study was more similar to a real clinical setting than the first study was because we performed the thinning procedure without guidance from a contrast distribution in the second 
study. Nojima et al. [20] performed a similar cadaveric study and found the vascular territories of the ALT flaps in their cadavers to decrease when compared to their clinical cases. They stated that the vascular territories likely decreased because the cadavers were relatively old and not healthy at their time of death [20].

Rees and Taylor [21] and Bergeron et al. [22] suggest mixing lead oxide for injection into the perforator vessels of cadavers. We had difficulties obtaining a lead oxide contrast liquid, so we

\section{Fig. 3. Radiograph of one flap after the thinning procedure}

One flap from the second cadaveric study shows sufficient distribution of the contrast across the surface of the flap.

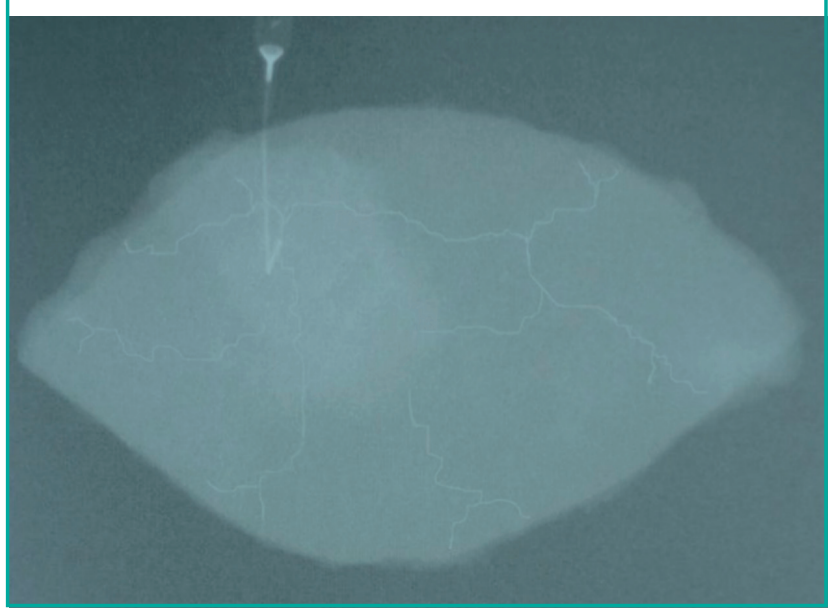

used a mixture of barium, latex, and gelatin. Although the contrasting appearance was not evenly distributed on the radiograph, it was sufficient for our purpose.

In the clinical series, $20-35$ minutes were needed to perform the thinning procedure for the $14 \mathrm{ALT}$ and $1 \mathrm{MSAP}$ flaps ranging from $7 \mathrm{~cm} \times 5 \mathrm{~cm}$ to $18 \mathrm{~cm} \times 12 \mathrm{~cm}$ in dimension. This time required to perform these procedures is typical for flap thinning procedures. The average percentage of post-reduction thickness was $37.91 \% \pm 7.15 \%$, which is closer to that of the first cadaveric study $(32.76 \% \pm 9.76 \%$ for the ALT flaps) than that of the second cadaveric study ( $52.51 \% \pm 5.97 \%$ for the ALT flaps).

Most of the flaps in our series yielded favorable outcomes, in which the flap survived with a good aesthetic contour. However, two cases did not have satisfactory results. Although case number 8 had the smallest flap dimensions, it had a bulky appearance. In this case, a bulky flap was unavoidable due to longstanding edema, which might have been caused by a possible decrease in venous and lymphatic back flow. As a result, unresolved edema with inherent fibrosis created a bulky appearance. In a larger series, Hong et al. [23] reported that six of 282 thin perforator flaps harvested at the superficial fascial plane required secondary debulking procedures.

Although no patient in our clinical series was considered overweight or obese, body mass index might influence the thickness of the superficial and deep fat layers; nonetheless, further study is

Fig. 4. Thinning procedure

(A) Macroscopic flap thinning performed by discarding the deep fat layer in case number 14. The perforator was safely preserved by leaving a 2-cm cuff of fat tissue. The prethinned flap thickness was $26 \mathrm{~mm}$. (B) The flap was thinned by separating the deep fat layer from the superficial fat layer. (C) Flap thickness was $10 \mathrm{~mm}$ after thinning.
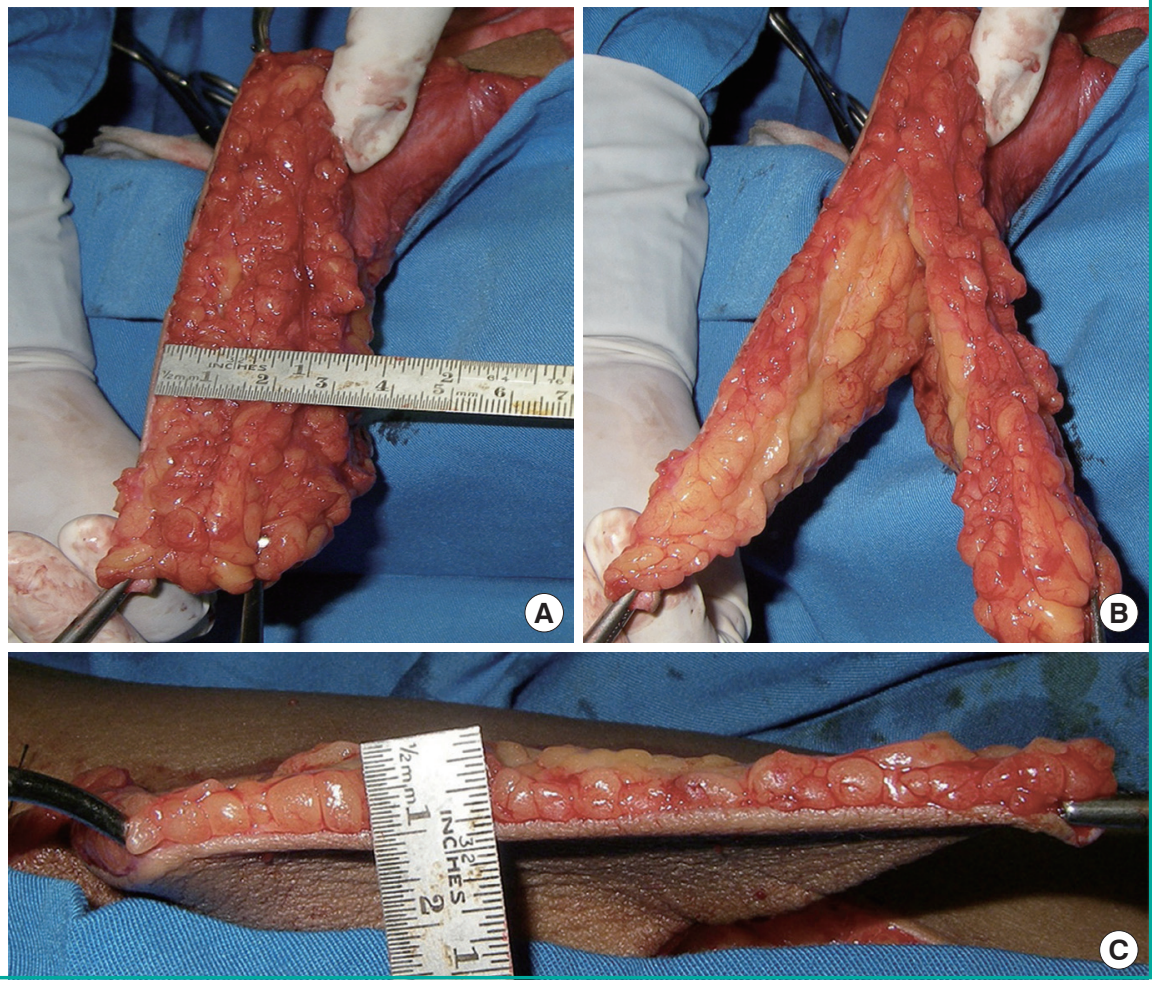


\section{Fig. 5. Thinned flap for the foot dorsum}

(A) A 25-year-old male with a traumatic soft tissue defect on his right dorsum (case number 1). An $18 \mathrm{~cm} \times 12 \mathrm{~cm}$ anterolateral thigh perforator flap was used to heal the defect. (B) The medial profile of the foot a week after surgery. (C) Frontal view of the final outcome while weight bearing. (D) Lateral profile view of the final outcome.
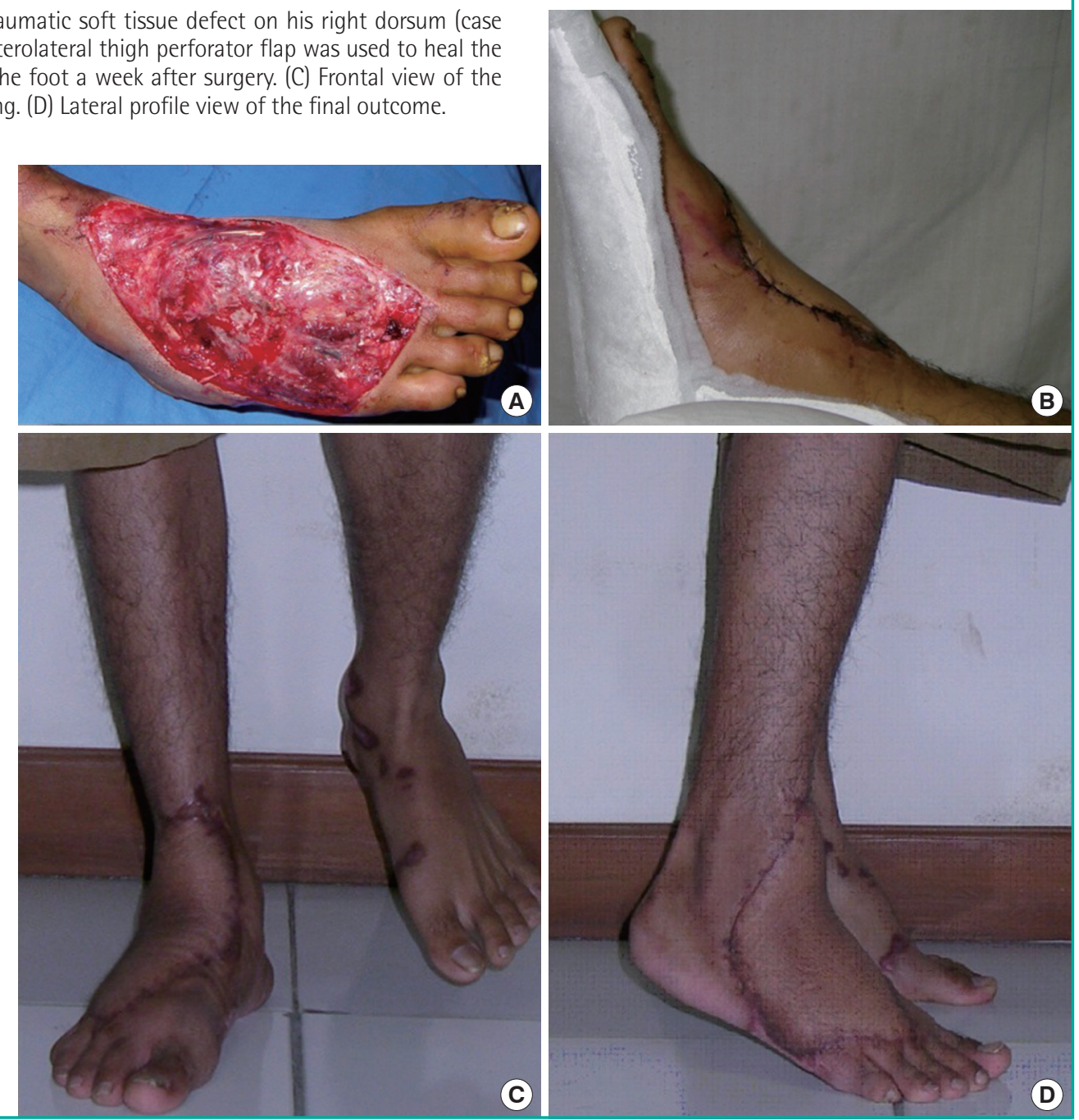

needed. Body mass index might influence the thickness of the superficial and deep fat layers; nonetheless, further study is needed. Moreover, we did not investigate the potential confounding effect of body mass index, but was still able to achieve a 30\%$50 \%$ reduction of flap thickness in this macroscopic thinning procedure.

The flap in case number 3 failed to survive and might have resulted from a complication during the macroscopic thinning procedure. However, many possible causes might have contributed to this failure, such as vein thrombosis. In general, the anatomy of the perforator flap vasculature is applicable to all kinds of perforator flaps; hence, the authors considered the MSAP flap failure to be a coincidence since it can also result in other types of perforator flaps.

We demonstrated that the deeper fat layer could be safely removed without interrupting the vascularization of a perforator flap, if a 2-cm cuff of fat tissue surrounding the perforator vessel is preserved. This evidence may guide surgeons to achieve thin yet viable flaps using the macroscopic flap thinning technique. We believe that this finding adds to the knowledge surrounding the fast revolution of the flap thinning technique. Our clinical series suggests that such a macroscopic flap thinning technique can be performed safely.

\section{REFERENCES}

1. Chen HC, Tang YB, Mardini S, et al. Reconstruction of the hand and upper limb with free flaps based on musculocutaneous perforators. Microsurgery 2004;24:270-80.

2. Koshima I, Nanba Y, Tsutsui T, et al. Perforator flaps in lower extremity reconstruction. Handchir Mikrochir Plast Chir 2002;34:251-6.

3. Hamdi M, Van Landuyt K, Monstrey S, et al. A clinical experience with perforator flaps in the coverage of extensive 
defects of the upper extremity. Plast Reconstr Surg 2004; 113:1175-83.

4. Gedebou TM, Wei FC, Lin CH. Clinical experience of 1,284 free anterolateral thigh flaps. Handchir Mikrochir Plast Chir 2002;34:239-44.

5. Wolff KD, Kesting M, Thurmuller P, et al. The anterolateral thigh as a universal donor site for soft tissue reconstruction in maxillofacial surgery. J Craniomaxillofac Surg 2006;34: 323-31.

6. Kimura N. A microdissected thin tensor fasciae latae perforator flap. Plast Reconstr Surg 2002;109:69-77.

7. Koshima I, Yamamoto T, Narushima M, et al. Perforator flaps and supermicrosurgery. Clin Plast Surg 2010;37:683-9.

8 . Hong JP. The use of supermicrosurgery in lower extremity reconstruction: the next step in evolution. Plast Reconstr Surg 2009; 123:230-5.

9. Hong JP, Chung IW. The superficial fascia as a new plane of elevation for anterolateral thigh flaps. Ann Plast Surg 2013; 70:192-5.

10. Kimura N, Saito M, Itoh Y, et al. Giant combined microdissected thin thigh perforator flap. J Plast Reconstr Aesthet Surg 2006;59:1325-9.

11. Alkureishi LW, Shaw-Dunn J, Ross GL. Effects of thinning the anterolateral thigh flap on the blood supply to the skin. Br J Plast Surg 2003;56:401-8.

12. Gasperoni C, Gasperoni P. Subdermal liposuction: longterm experience. Clin Plast Surg 2006;33:63-73.

13. Kimura N, Satoh K. Consideration of a thin flap as an entity and clinical applications of the thin anterolateral thigh flap. Plast Reconstr Surg 1996;97:985-92.

14. Ross GL, Dunn R, Kirkpatrick J, et al. To thin or not to thin: the use of the anterolateral thigh flap in the reconstruction of intraoral defects. Br J Plast Surg 2003;56:409-13.

15. Nakayama B, Hyodo I, Hasegawa Y, et al. Role of the anterolateral thigh flap in head and neck reconstruction: advantages of moderate skin and subcutaneous thickness. J Reconstr Microsurg 2002;18:141-6.

16. Kimura N, Satoh K, Hasumi T, et al. Clinical application of the free thin anterolateral thigh flap in 31 consecutive patients. Plast Reconstr Surg 2001;108:1197-208.

17. Itoh Y, Arai K. The deep inferior epigastric artery free skin flap: anatomic study and clinical application. Plast Reconstr Surg 1993;91:853-63.

18. Zaretski A, Wei F-C, Lin C-H, et al. Anterolateral thigh perforator flaps in head and neck reconstruction. Semin Plast Surg 2006;20:64-72.

19. Kim HH, Jeong JH, Seul JH, et al. New design and identification of the medial sural perforator flap: an anatomical study and its clinical applications. Plast Reconstr Surg 2006; 117:1609-18.

20. Nojima K, Brown SA, Acikel C, et al. Defining vascular supply and territory of thinned perforator flaps: part I. Anterolateral thigh perforator flap. Plast Reconstr Surg 2005;116: 182-93.

21. Rees MJ, Taylor GI. A simplified lead oxide cadaver injection technique. Plast Reconstr Surg 1986;77:141-5.

22. Bergeron L, Tang M, Morris SF. A review of vascular injection techniques for the study of perforator flaps. Plast Reconstr Surg 2006;117:2050-7.

23. Hong JP, Choi DH, Suh H, et al. A new plane of elevation: the superficial fascial plane for perforator flap elevation. J Reconstr Microsurg 2014;30:491-6. 